\title{
Phagocytosis as a potential mechanism for microbial defense of mouse placental trophoblast cells
}

\author{
A Amarante-Paffaro, G S Queiroz, S T Corrêa, B Spira ${ }^{1}$ and E Bevilacqua \\ Department of Histology and Embryology and ${ }^{1}$ Department of Microbiology, Institute of Biomedical Sciences, \\ University of São Paulo, São Paulo, Brazil
}

Correspondence should be addressed to E Bevilacqua; Email: bevilacq@usp.br

\begin{abstract}
Trophoblast giant cells are active phagocytes during implantation and post-implantation. Phagocytosis decreases during placental maturation as the phagocytic function of nutrition is gradually replaced by the direct uptake of nutrients by the labyrinth zone trophoblast. We hypothesize that, after placental maturation, trophoblast cells maintain phagocytic functions for purposes other than nutrition. This study employs histological techniques to examine the ability of trophoblast cells to phagocytose microorganisms (yeast or bacteria) - in vivo in females receiving thioglycolate to activate macrophages and in vitro in the presence of phagocytic promoters such as interferon- $\gamma$ and complement component C3. Placental trophoblast cells from the second half of gestation show basal phagocytosis that can be dramatically up-regulated by these promoters when microorganisms are inoculated into pregnant animals or introduced into culture systems. Stimulated trophoblast cells phagocytosed organisms more rapidly and in greater numbers than non-stimulated trophoblast exposed to the same numbers of organisms. Taken together, our results indicate that trophoblast cells do not lose their ability to phagocytose during the placentation process, which may imply that trophoblast cells participate in embryonic and fetal innate immune defense through elimination of microorganisms present at the maternal-fetal interface.
\end{abstract}

Reproduction (2004) 128 207-218

\section{Introduction}

In mice and other rodents, trophoblast giant cells are the placental cells in direct contact with endometrial tissues throughout gestation (Billington 1971, Muntener \& Hsu 1977). These cells play crucial roles in implantation and placentation (Muntener \& Hsu 1977, Bevilacqua \& Abrahamsohn 1988, Mehrotra 1988, Kanai-Azuma et al. 1994). After the onset of implantation, phagocytosis of maternal components (cells interposed in the invasion pathway, as well as substantial numbers of blood cells) develops in trophoblast giant cells. The highest levels of phagocytosis have been recorded between 7.5 and 8.5 days of gestation (Enders \& Schlafke 1969, Welsh \& Enders 1987, Bevilacqua \& Abrahamsohn 1988). It has been reported that this phagocytic activity participates in fetal nutrition prior to complete formation of the placenta. This phagocytic activity also plays a role in acquiring space for embryo attachment and development in the endometrium (Welsh \& Enders 1987, Bevilacqua \& Abrahamsohn 1988, 1989).

Over the course of gestation, phagocytic activity decreases significantly, whereas other functional features such as endocrine activity become more prominent (Soares \& Glasser 1987, Soares et al. 1993, 1996, KanaiAzuma et al. 1994). From a nutritional viewpoint, this decrease is consistent with the differentiation of the placental labyrinth zone, where definitive molecular exchanges are established.

Under in vitro conditions, erythrophagocytosis by rodent trophoblast giant cells has been observed in the presence of lipopolysaccharides (either alone or combined with interferon- $\boldsymbol{\gamma}(\mathrm{IFN}-\boldsymbol{\gamma})$ ), phorbol myristate acetate and all-trans-retinal (Albieri \& Bevilacqua 1996, Gagioti et al. 1996, Albieri et al. 2001). Once phagocytic, trophoblast cells produce and release reactive oxygen and nitrogen species such as superoxide anion, hydrogen peroxide and nitric oxide, suggesting that trophoblast phagocytosis plays a role in microbial defense mechanisms (Gagioti et al. 1995, 1996, 2000). Under in vitro conditions, trophoblast cells are able to phagocytose microorganisms (Drake \& Rodger 1987), reinforcing the hypothesis of a possible trophoblast defense mechanism that contributes to removal of infectious agents from the fetal-maternal interface (Simmons \& Russel 1962, Pavia 1983, Guilbert et al. 1993, Kanai-Azuma et al. 1994). 
In addition to phagocytosis, there are many characteristics that trophoblast giant cells have in common with macrophages, including the ability to invade tissues and the potential for producing or responding to specific regulatory proteins. Such proteins include granulocyte macrophage-colony stimulating factor (GM-CSF) (Athanassakis et al. 2000), colony stimulating factor-1 (CSF-1) (Athanassakis-Vassiliadis et al. 1993, Athanassakis et al. 2000, Guleria \& Pollard, 2000, Sasmono et al. 2003), interleukin (IL)-1 (Paulesu et al. 1991, Yamaguchi et al. 1996), IL-6 (Yamaguchi et al. 1996), tumor necrosis factor $\alpha$ and $\beta$ (Kohchi et al. 1991, Whiteside et al. 2003), and transforming growth factor $\alpha$ and $\beta$ (Sharma, 1998, Schaffer et al. 2003). These lineages share the markers CD4 and CD14 (Athanassakis et al. 1990, Clark et al. 2003), produce specific esterases, and possess receptors for IgG (FcR) (Guilbert et al. 1993), C3b complement system particle (Albieri et al. 1999) and for IFN- $\gamma$ (Athanassakis et al. 2000, Albieri et al. 2001). These shared properties have led to the hypothesis that trophoblast cells, although different in lineage from macrophages, are part of a microbial defense system (Guilbert et al. 1993, Guleria \& Pollard 2000, Sasmono et al. 2003). Few studies have investigated the degree to which trophoblast cells may contribute to fetal defense. We hypothesized that trophoblast cells, after placental maturation, maintain phagocytic activity associated with functions other than nutrition. In this report, we experimentally demonstrate the ability of mid-gestation trophoblast cells to phagocytose yeast cells Saccharomyces cerevisiae and bacteria Escherichia coli in the presence of promoters of phagocytosis in vivo and in vitro.

\section{Materials and Methods}

\section{Animals}

Swiss mice (Mus musculus domesticus), 2 months of age, were acquired from the Animal Care Center of the State University of Campinas (CEMIB-UNICAMP, São Paulo, Brazil). Females were caged overnight with males $(1: 1)$ and successful mating was verified the following morning. The presence of a vaginal plug was designated as day 0.5 of pregnancy. For the in vivo challenge studies, 56 pregnant females were used; 10 were used for the culture studies. All procedures were carried out in accordance with the guidelines of the Brazilian College of Animal Experimentation (COBEA) and were authorized by the University of São Paulo Committee on Ethics in Animal Research.

\section{In vivo phagocytic assays involving S. cerevisiae}

Since mediators of immune and inflammatory responses could be of crucial importance in signaling and stimulating trophoblast cells, we tested the ability of the trophoblast to phagocytose yeast cells in vivo. The number of pregnant animals in each of the four experimental groups varied from 1 to 3 time point. In one group $(n=21)$, macrophages were previously activated by thioglycolate (Cohn, 1978, Cohen et al. 1981, Call et al. 2001, Salins et al. 2001). In this group, the animals received $300 \mu \mathrm{l} 4 \%$ sodium thioglycolate in sterile saline, i.p., on day 12.5 of gestation and after $15 \mathrm{~h} 300 \mu \mathrm{l}$ of a supersaturated solution of $S$. cerevisiae, administered i.v. Using the same routes of administration in the other three groups $(n=35)$ the pregnant females received, respectively, $300 \mu$ of the following solutions: saline solution and then yeast $(n=3$ mice/time point), thioglycolate followed by saline $(n=1$ mouse/time point) and saline followed by saline (control group, $n=1$ mouse/time point).

To quantify yeast particles, blood smears were prepared from tail blood. Test and control mice were topically anesthetized (5\% xylocaine, AstraZeneca Pharmaceutical Ind., São Paulo, SP, Brazil) and, under minimal stress, the tail skin was perforated with a 36-gauge needle. A few drops of blood were immediately collected and, after $15 \mathrm{~min}$, spread onto three histological slides. Blood collection was repeated at $1 \mathrm{~h}$ and some animals were immediately killed by cervical dislocation. Blood collection and subsequent death were then carried out at 2, 3, 6, 9 and $24 \mathrm{~h}$ after yeast administration. Placentas and spleens were collected for morphological studies and for tissue smears. For the smears, three fragments of placenta and spleen from each animal were macerated on a histological slide and washed in PBS to remove excess tissue. The remaining material was then air-dried, fixed in methanol and stained with Giemsa or hematoxylin-eosin. At the time of each assay, blood was collected from all living mice and their blood films were analyzed. For the morphological studies, some placentas and minced spleen fragments from each euthanized mouse were processed histologically.

\section{Light and electron microscopic analyses}

For light microscopic analysis, the placenta and spleen were cut into small fragments of $2-3 \mathrm{~mm}$ in thickness and $5-8 \mathrm{~mm}$ in length and fixed for $2 \mathrm{~h}$ in $4 \%$ paraformaldehyde (Sigma) in $0.1 \mathrm{M}$ PBS, pH 7.4, containing $0.1 \mathrm{M}$ sucrose. After fixation, the specimens were washed in PBS, dehydrated in ethanol and embedded in plastic resin (Historesin, Leica Microsystems Nusslock, Heidelberg, Germany) or paraplast (Merck Chemical Co., São Paulo, Brazil). Sections of $2 \mu \mathrm{m}$ in thickness were stained with $1 \%$ Toluidine blue in distilled water, or Giemsa. For ultrastructural studies, placentas and spleens were cut into 2$\mathrm{mm}^{3}$ fragments and fixed in $2 \%$ glutaraldehyde in $0.1 \mathrm{M}$ PBS, pH 7.4, containing $0.1 \mathrm{M}$ sucrose, for $12 \mathrm{~h}$, postfixed in $1 \%$ osmium tetroxide for $1 \mathrm{~h}$, dehydrated in ethanol and embedded in Spurr's resin (Sigma). The placentas were first cut into four quadrants and the fragments were obtained from the most angular region, in such a way that decidua, junctional zone and the labyrinth were always represented in 2 to 3 small fragments. The placental fragments obtained from each placental region were then 
carefully identified in separated flasks. For ultrastructural analyses, samples from each segment were randomly selected. Thin sections were stained with $1 \%$ uranyl acetate and $0.5 \%$ lead citrate, and examined in a JEOL CX-II-100 electron microscope.

\section{In vitro phagocytic assay involving $\mathrm{S}$. cerevisiae and E. coli}

Placental cells, obtained as described below, were cultured for $48 \mathrm{~h}$, then used for phagocytic assays employing $S$. cerevisiae and E. coli as targets for phagocytosis. The effects of IFN- $\gamma$ (Sigma) and complement component C3 (as normal mouse plasma prepared in our laboratory) on this phagocytic activity were also evaluated. Phagocytosis was quantified and qualitatively analyzed through morphological examination.

\section{Placental cell primary cultures}

Fragments from each day-13.5 placenta were cut into very small pieces in a laminar flow hood (Vecco Ind., Campinas, Brazil). The fragments were treated with $15 \mathrm{ml}$ trypsin (Instituto Adolfo Lutz, São Paulo, Brazil) in sterile tubes for $20 \mathrm{~min}$ at room temperature followed by $20 \mathrm{~min}$ incubation at $37^{\circ} \mathrm{C}$. The trypsin was then inactivated in Dulbecco's modified Eagle's medium (D-MEM, Sigma) containing 20\% fetal calf serum (FCS, Cultilab S.A., Campinas, Brazil) and the material was centrifuged at 1000 r.p.m. for $10 \mathrm{~min}$. The supernatant was resuspended in $1 \mathrm{ml}$ culture medium supplemented with FCS and introduced into a $60 \mathrm{~mm}$ culture plate containing six removable $18 \mathrm{~mm}$ diameter glass cover slips. The cultures were maintained under standard culture conditions for $48 \mathrm{~h}$ to allow attachment and spreading of the placental cells. The characterization of the trophoblast cells within the placental cell population was performed using morphological patterns associated with cytokeratin A-B immunolocalization.

\section{Immunolocalization of cytokeratin filaments}

Cells grown on the cover slips were fixed in $4 \%$ paraformaldehyde in $0.1 \mathrm{M}$ PBS, $\mathrm{pH} 7.2$, and washed several times in $0.02 \mathrm{M}$ TBS (tris-hydroxymethyl aminomethane buffered saline, Amersham Biosciences, Uppsala, Sweden), $\mathrm{pH}$ 8.2, containing $0.05 \%$ saponin (Polyscience Inc., Warrington, PA, USA). Blocking of endogenous alkaline phosphatase was verified by incubation for $8 \mathrm{~min}$ in $5 \%$ acetic acid, and that of nonspecific binding by incubation for $1 \mathrm{~h}$ at $37^{\circ} \mathrm{C}$ with TBS- $1 \%$ bovine serum albumin (BSA, Sigma) containing $0.05 \%$ saponin and $0.2 \%$ glycine, $\mathrm{pH}$ 8.2. Rat IgG anti-mouse cytokeratin A-B (Troma, DSHB, University of lowa, lowa City, IA, USA) was used as the primary antibody at a dilution of 1:10 and incubated at $4{ }^{\circ} \mathrm{C}$ overnight. The secondary antibody used was either biotinylated anti-rat $\lg \mathrm{G}$ or Cy3 anti-rat $\lg \mathrm{G}$ (both from Sigma), at $37^{\circ} \mathrm{C}$ for $1 \mathrm{~h}$ of incubation. The material receiving the biotinylated antibody was developed using an
$A B C$ kit (alkaline phosphatase-avidin-biotin complex, BioStain Super kit, Biomeda Co., Foster City, CA, USA) as recommended by the manufacturer and analyzed by conventional light microscopy. Cytokeratin-positive cells were counted in random areas and expressed as a percentage of the total number per microscopic field for each pregnant animal. Cytokeratin characterization was carried out after culture preparation of at least one coverslip from each placenta.

\section{Phagocytic assays involving S. cerevisiae}

The phagocytic assays were performed using $S$. cerevisiae (zymosan), either conjugated with Texas-red (Molecular Probes, Eugene, OR, USA) or unlabeled (Sigma) at a concentration of $7 \times 10^{5}$ particles/culture dish, for direct observation by fluorescence or light/electron microscopy respectively. In the experimental groups, IFN- $\gamma(100 \mathrm{U} / \mathrm{ml})$ was added to the culture medium $12 \mathrm{~h}$ before zymosan inoculation. To test the effect of the complement component $\mathrm{C} 3$ on phagocytosis by the placental trophoblast, yeast cells pre-treated with $\mathrm{C} 3$-sufficient mouse plasma $(20 \mu \mathrm{l} / \mathrm{ml})$, either alone or combined with IFN- $\gamma$, were also used as an additional treatment. Control cultures received either only zymosan particles or no treatment. To obtain opsonized-zymosan particles, zymosan was pretreated according to techniques described by Albieri and coworkers (1999). The final product formed C3b-bound zymosan (Lima \& Dias-da-Silva 1970) and was used in the phagocytic assays at the particle concentration mentioned above. Each experimental treatment was then analyzed 1, 2, 3, 6, 9 and $24 \mathrm{~h}$ after introduction of the yeast into the culture system, creating 18 experimental and 12 control groups. For each group, samples were assayed in triplicate.

The ability of placental cells to ingest zymosan particles was measured by counting the total number of cytokeratin-positive cells, as well as the total number of cytokeratin-positive cells containing internalized yeast cells, per microscopic field in a total of 10 random fields/ culture dish. The phagocytic index (PI) was calculated as the percentage of trophoblast cells within the trophoblast population, which contained phagosomes $(\mathrm{PI}=$ number of trophoblast cells with zymosan-internalized particles $\times 100 /$ total number of trophoblast cells). Counts were performed using a Nikon Optiphot light microscope or a Nikon eclipse E800 fluorescence microscope at a final magnification of $400 \times$. Results are given in the text as means \pm S.D. The mean values obtained for each experiment were compared with the control using ANOVA. Values of $P<0.05$ were considered significant. For morphological and quantitative assays, the specimens incubated with Texas red-zymosan particles were fixed in $4 \%$ paraformaldehyde, counterstained with 4',6-diamidino-2phenylindole (DAPI, Sigma) for observation by fluorescence microscopy or counterstained with $1 \%$ Toluidine blue for conventional light microscopy and mounted on histological slides with Diazabicyclo [2.2.2] octane 
(DABCO, Sigma). All specimens that received fluorescent particles (zymosan or E. coli) were also submitted to concomitant cytokeratin immunodetection as previously described. Some cultures were also prepared for electron microscopy to accompany the stages of the zymosan internalization.

\section{Ultrastructural studies}

Cultured cells were gently scraped from the culture dish and inserted into $2 \%$ soft agarose (Gibco, USA) in PBS. After gelling, the agar was cut into small fragments and prepared as previously described for embedding in Spurr's resin. Ultrathin (60-nm) sections were stained with $0.2 \%$ uranyl acetate and $0.5 \%$ lead citrate before examination in a JEOL CX-II-100 electron microscope.

\section{Phagocytic assays using E. coli}

To follow the progression of phagocytosis of bacterial cells by the placental trophoblast, bacteria expressing green fluorescent protein (GFP) were used (Ouahrani-Bettache et al. 1999). Since GFP absorbs light at a maximum excitation of $395 \mathrm{~nm}$ and fluoresces at a maximum emission of $510 \mathrm{~nm}$, it permits the visualization of a single bacterium under a fluorescence microscope. Plasmid pRL1, which contains the GFP gene under the strong inducible promoter (Ptac) was constructed and introduced into E. coli. The transfected cells were grown overnight in LB medium supplemented with ampicillin and chloramphenicol. Addition of isopropylthio- $\beta$ galactosidase (IPTG) to the culture was not necessary because the bacteria expressed GFP even in the absence of the inducer, probably due to the natural leakiness of Ptac. Bacteria $\left(1 \times 10^{5}\right)$ were introduced into each of the following trophoblast cell cultures: treated with IFN- $\gamma$ for $12 \mathrm{~h}$, treated with C3-sufficient-plasma for $12 \mathrm{~h}$, treated with IFN- $\gamma$ and C3-sufficient-plasma for $12 \mathrm{~h}$, and untreated. To obtain C3-sufficient plasma, mouse plasma was collected as described by Albieri and co-workers (1999) and added to the culture medium at a concentration of $10 \%$, without previous heat-inactivation. At 1, 2, 3, 6, 9 and $24 \mathrm{~h}$ after the introduction of $E$. coli into the culture system, the cells were harvested, fixed in $4 \%$ paraformaldehyde and submitted to immunofluorescence procedures for cytokeratin A-B localization, mounted on histological slides with DABCO, and observed under a fluorescence microscope. Bacterial phagocytosis was observed either by the green fluorescent light emitted by the cloned GFP under a fluorescence microscope or with a JEOL CX-II-100 electron microscope as described above.

\section{Construction of plasmid $p R L 1$}

Plasmid pRL1 was constructed by introducing Ptac into the polylinker of plasmid pBBR1-GFP (Ouahani-Bettache et al. 1999). Plasmid pBBR1-GFP carries a small polylinker followed by the promoterless GFP and chloramphenicol acetyl transferase (CAT) genes in tandem. Introduction of a promoter sequence at the polylinker site in the right orientation enhances the synthesis of both GFP and CAT proteins. A 270-bp DNA fragment containing Ptac was obtained by digesting plasmid pKK223-3 (Amersham) with BamHI (MBI-Fermentas). The Ptac was then ligated to the polylinker of plasmid pBBR1-GFP previously digested with Bglll (MBI-Fermentas, Vilnius, Lithuania). The product of the ligation was electroporated into electrocompetent DH10B E. coli, which were plated on LB plates supplemented with $100 \mu \mathrm{g} / \mathrm{ml}$ ampicillin, $20 \mu \mathrm{g} / \mathrm{ml}$ chloramphenicol and $1 \mathrm{mM}$ IPTG. The pRL1-transformed cells that expressed both CAT and GFP proteins were used in the phagocytic assays.

\section{Results \\ In vivo assays}

The persistence of yeast cells in the circulation of the pregnant mice and in specific tissues was evaluated in blood and in spleen and placental smears. Three hours after intravenous yeast cell inoculation, the vascular blood still contained a large number of particles (Fig. 1a, b). Animals treated with thioglycolate presented leukocyteattached particles and internalized yeast cells (Fig. 1b, inset). This occurred 3-6h earlier in treated animals than in controls (data not shown). Yeast cells were also found in the spleen and in fetal and maternal components of the placenta. In the spleen, free and phagocytosed yeast cells were seen in both the thioglycolate-stimulated and nonstimulated experimental groups throughout the entire period analyzed (data not shown). From $6 \mathrm{~h}$ after inoculation, yeast cells seen in placental smears were apparently attached to leukocytes or trophoblast cells, or were still internalized in the cytoplasm of such cells (Fig. 1c, d). Paraplast placental sections (Fig. 1e, f) and ultrastructural analysis (Fig. 1g) also confirmed yeast access to the extravascular placental spaces and yeast internalization into the trophoblast cell cytoplasm.

\section{In vitro assays}

There are only two cell populations in the placenta that exhibit cytokeratin intermediate filaments, trophoblast and yolk sac endodermal cells. Since endodermal cells exhibit a very peculiar, spheroid morphology that allows easy morphological identification, we were able to estimate the percentage of trophoblast cells growing in the primary placental culture by analyzing the morphology of the cytokeratin-positive cells. At least 85\% of the placental cells were cytokeratin A-B positive (Fig. 2a-c) and were morphologically distinct from the endodermal cells. Most of the negative cells presented a fibroblast typical morphology $(14 \%)$ and the remaining cells (less than 1\%) probably included decidual cells, endothelial cells, macrophages and uterine NK 

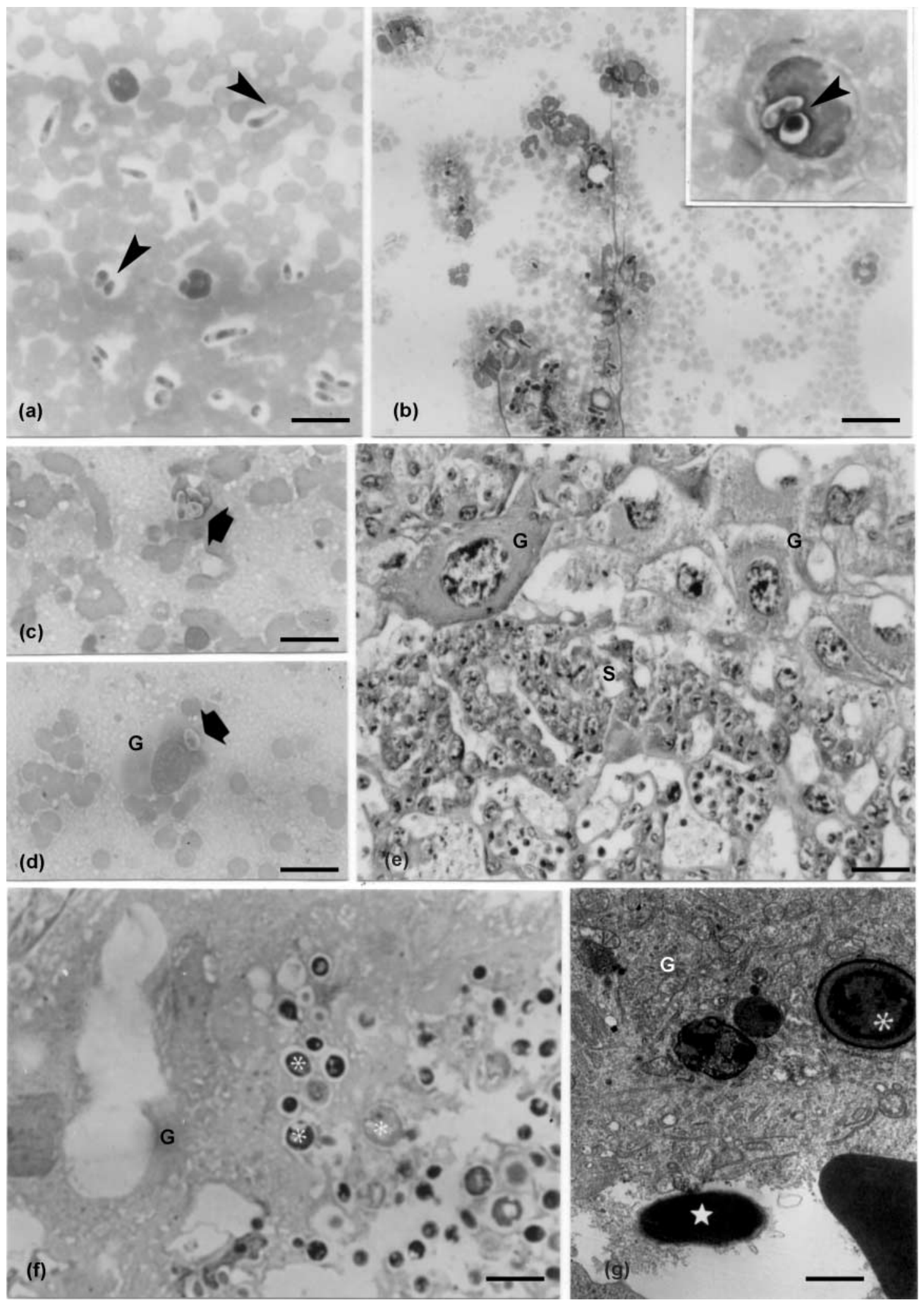

Figure 1 Giemsa-stained samples $(\mathrm{a}, \mathrm{b})$, obtained $3 \mathrm{~h}$ after intravenous inoculation with $\mathrm{S}$. cerevisiae, show yeast cells (a, arrowheads) still free in the blood smears from animals not receiving thioglycolate, but already attached to or internalized (b, inset) within leukocytes in thioglycolate-stimulated animals. Six hours after yeast inoculation, placental smears (c, d) show particles apparently attached (arrows) to (c) placental leukocytes and (d) trophoblast giant cells $(\mathrm{G})$. Paraplast-embedded placental sections (e, f) and ultra-thin placental sections (g) confirm the presence of internalized particles (asterisks) within trophoblast giant cells (G). S, spongiotrophoblast cells. (Star) Erythrocyte. Scale bars represent (a, c, d) $20 \mu \mathrm{m}$, (b) $40 \mu \mathrm{m}$, (inset) $6.5 \mu \mathrm{m}$, (e) $30 \mu \mathrm{m}$, (f) $15 \mu \mathrm{m}$, (g) $1.5 \mu \mathrm{m}$. 

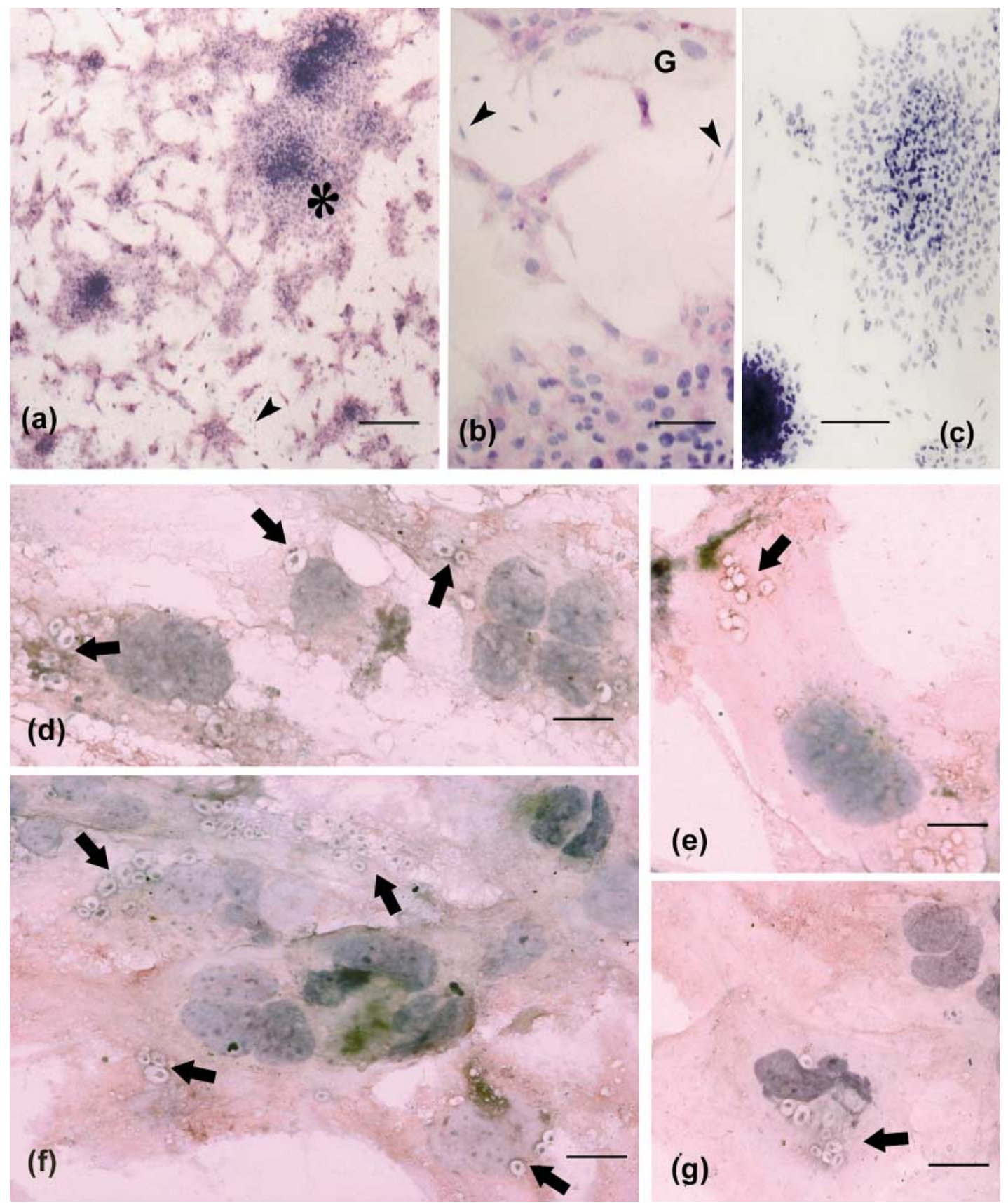

Figure 2 Placental cell culture. ( $a, b$ and c) Low magnification views of cultures processed for anti-cytokeratin immunoreaction, showing (a, b) the predominance of cytokeratin reactive cells (trophoblast) over non-reactive cells (non-trophoblast placental cells, arrowheads). Note also the peculiar disposition of the placental cells after culturing: labyrinth trophoblast cells arranged in large clusters $(*)$ and other trophoblast and nontrophoblast placental cells spread throughout the culture; (c) the presence of only non-immune reactive cells when the anti-cytokeratin A-B primary antibody was removed from the immunoreaction. ( $\mathrm{d}$ to g) The phagocytic behavior of trophoblast cells in culture $6 \mathrm{~h}$ after $S$. cerevisiae inoculation. The cultures were respectively treated with (d) zymosan, (e) zymosan plus $100 \mathrm{U} / \mathrm{ml}$ IFN- $\gamma$, (f) C3-opsonized zymosan particles and (g) C3-opsonized zymosan particles plus $100 \mathrm{U} / \mathrm{ml}$ IFN- $\gamma$. The arrows show zymosan particles. Scale bars represent (a) $200 \mu \mathrm{m},(\mathrm{b}) 120 \mu \mathrm{m}$, (c) $160 \mu \mathrm{m},(\mathrm{d}, \mathrm{g}) 15 \mu \mathrm{m}$, (e) $30 \mu \mathrm{m}$, (f) $20 \mu \mathrm{m}$.

cells. In all experimental phagocytic assays, the phagocytosis exhibited by the placental cells was estimated in cells morphologically identified as trophoblast cells containing cytokeratin-positive filaments.

In all experimental groups, $S$. cerevisiae and $E$. coli cells were phagocytosed by placental trophoblast non-giant
(Fig. 2d, f) and giant cells (Fig. 2e, g). In general, non-giant cells displayed features similar to labyrinth zone cells, either organized in clusters, with cellular limits of difficult distinction and resembling a syncytial disposition (Fig. 2d,f), or as individual cells (Fig. 2e, g). However, the number of cells exhibiting phagocytic activity, as well as 

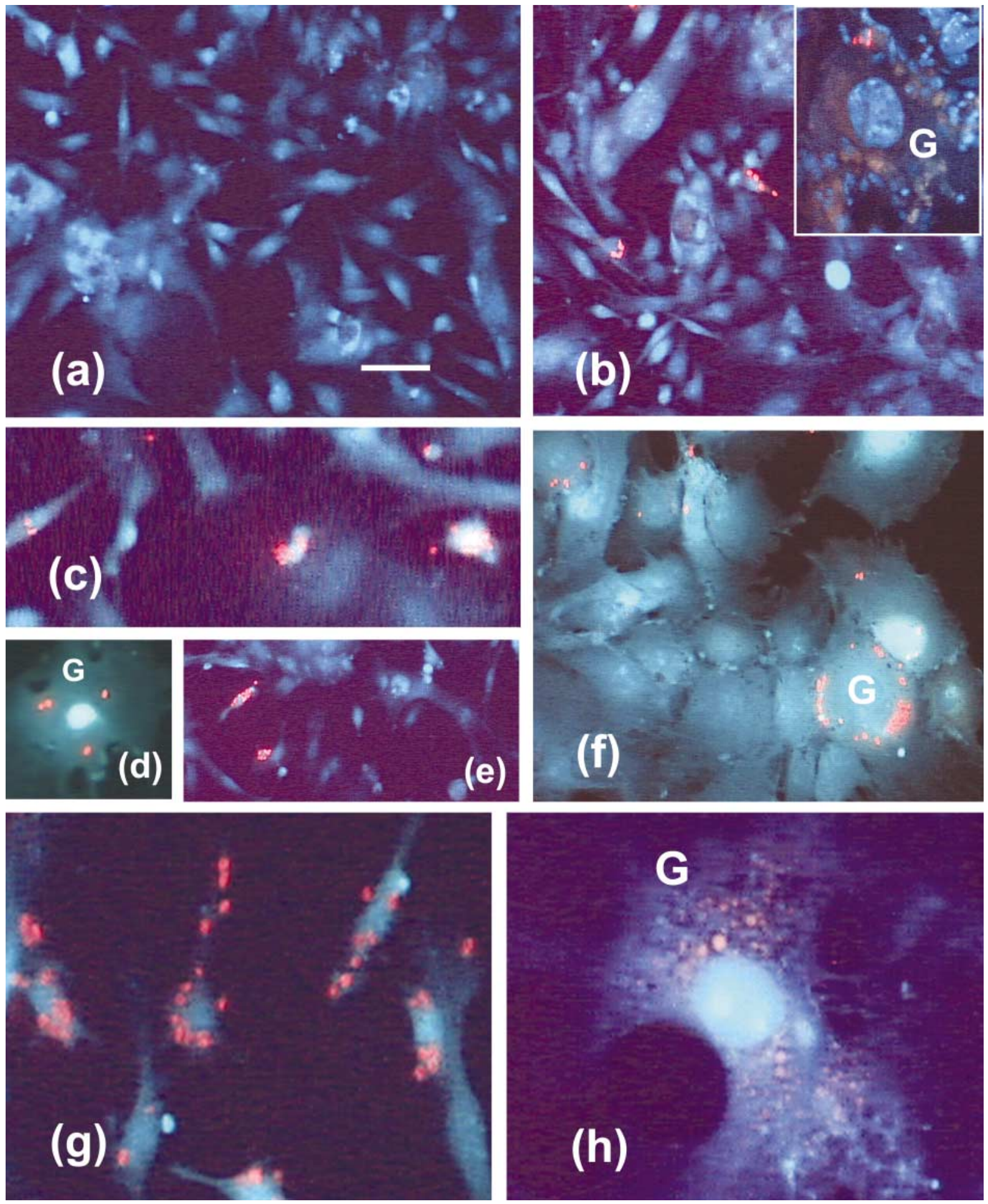

Figure 3 Placental culture $6 \mathrm{~h}$ after $S$. cerevisiae inoculation. $(\mathrm{a}-\mathrm{h})$ The following experimental culture groups are represented: (a) negative control (no yeast cells added to the culture), (b, inset) addition of yeast cells, (c, d) addition of yeast cells and IFN- $\gamma$, (e, f) addition of yeast cells and C3, (g, h) addition of yeast cells, IFN- $\gamma$ and C3. G, trophoblast giant cell. Scale bar in (a) represents: (a, b) $25 \mu \mathrm{m}$, (inset) $30 \mu \mathrm{m},(\mathrm{c}) 18 \mu \mathrm{m}$ (d, e) $35 \mu \mathrm{m},(\mathrm{f}) 20 \mu \mathrm{m},(\mathrm{g}, \mathrm{h}) 15 \mu \mathrm{m}$. 


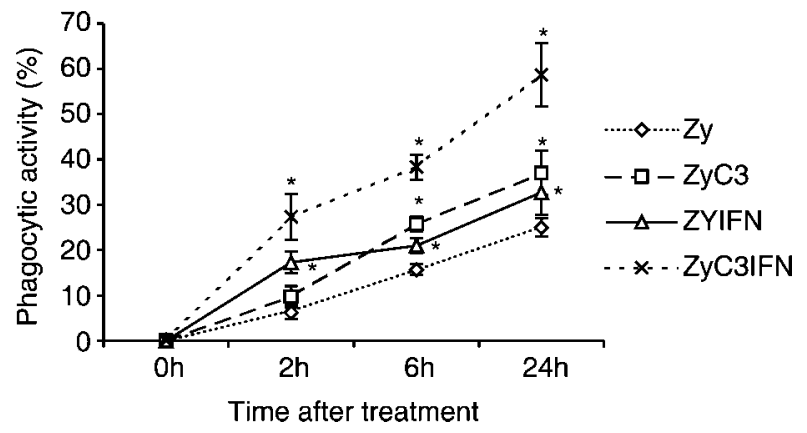

Figure 4 Comparison of phagocytic indices for cultured placental trophoblast cells subjected to different treatments, using zymosan particles as a target. Data are expressed as means \pm S.D. of at least 3 different experiments. $* P<0.05$ compared with control group receiving the target particle alone, at the same experimental interval. Zy, zymosan. the number of phagosomes, varied markedly as a function of the experimental treatment, time of exposure to the phagocytic agent and type of particle (Figs 2-6).

At all intervals, a low rate of phagocytosis was observed when only zymosan particles were added to the cultures (Fig. 3b, inset). Addition of IFN- $\gamma$ and/or C3-opsonized particles significantly altered the percentage of cells exhibiting phagocytic activity (Fig. 3c-h, Fig. 4). At the morphological level, it was also observed that the numbers of internalized particles per cell were altered (Fig. 3). At 6 and $24 \mathrm{~h}$ of treatment, C3-opsonized particles stimulated an approximate 1.5 -fold increase in the phagocytic activity of the cultured cells $(P<0.05)$, whereas IFN- $\gamma$ apparently led to earlier alterations (Fig. 4). At $2 \mathrm{~h}$ after the IFN- $\gamma$ stimuli, there was a 2.7 -fold increase $(P<0.05)$ in the phagocytic rate of the placental cells, followed by a
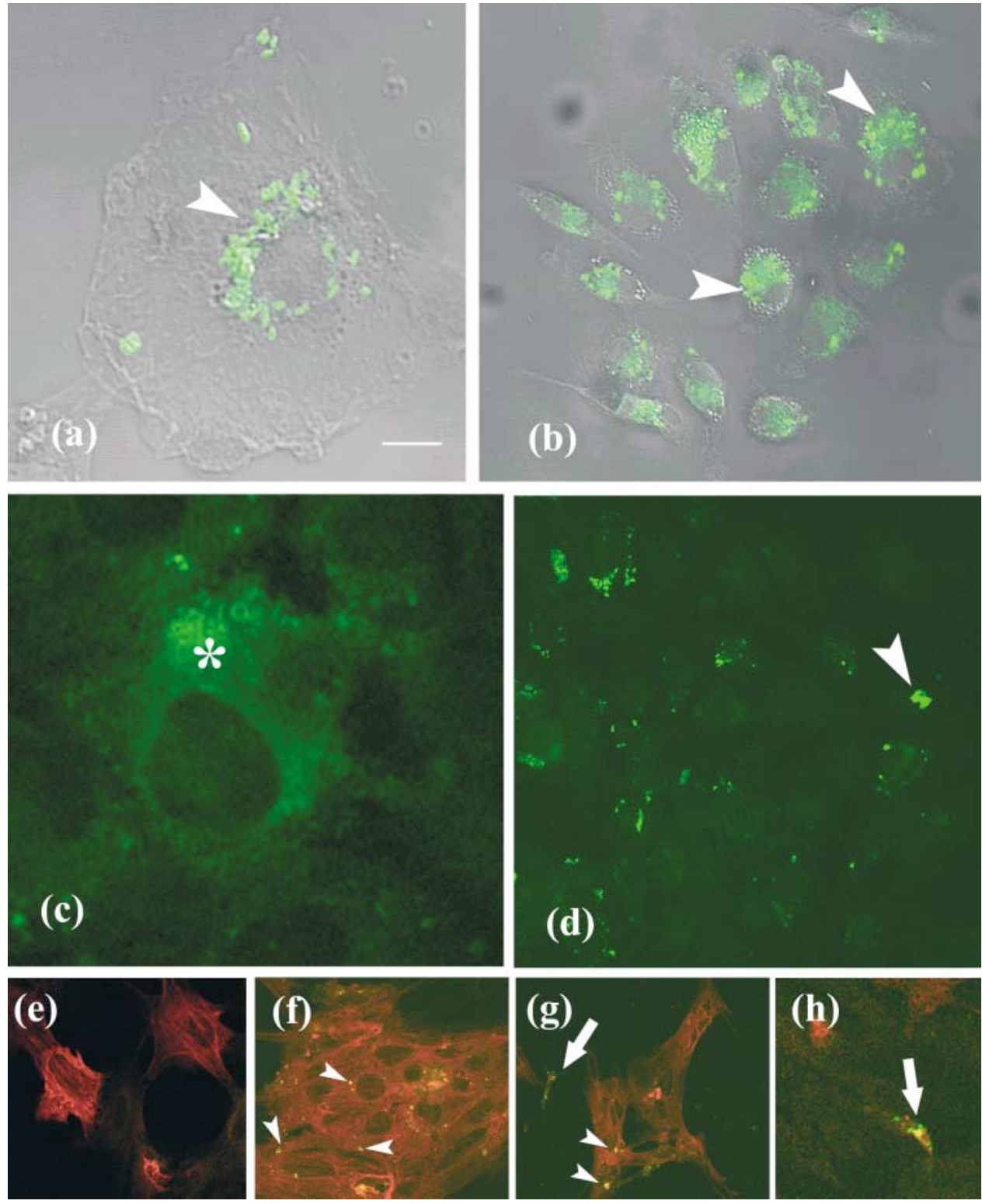

Figure 5 Placental culture after $E$. coli inoculation. $(a-d)$ The time course of phagocytosis shown by trophoblast giant $(\mathrm{a}, \mathrm{c})$ and nongiant $(b, d)$ cells using E. coli (arrowheads) as a target (a, b, $3 \mathrm{~h}$ and $\mathrm{c}, \mathrm{d}, 6 \mathrm{~h}$ after $E$. coli inoculation). Note that $6 \mathrm{~h}$ after introduction of the bacteria to the culture medium $(\mathrm{c}, \mathrm{d})$, dispersed material $(\mathrm{c}, *)$ or very few labeled particles ( $d$, arrowhead) can be seen in the trophoblast cytoplasm. Double labeling $(\mathrm{e}-\mathrm{h})$ reveals groups of cytokeratin-positive cells in the control (e) and treated cultures $(f-h)$ containing the fluorescent bacteria within their vacuoles (arrowheads). The arrows in (g) and (h) show a small cytokeratin-negative cell, probably a placental macrophage, also

containing fluorescent bacteria. Scale bar in (a) represents: $(\mathrm{a}, \mathrm{c})$ $10 \mu \mathrm{m},(\mathrm{b}, \mathrm{f}) 20 \mu \mathrm{m},(\mathrm{d}-\mathrm{e}, \mathrm{g})$ $50 \mu \mathrm{m}$, (h) $150 \mu \mathrm{m}$. 

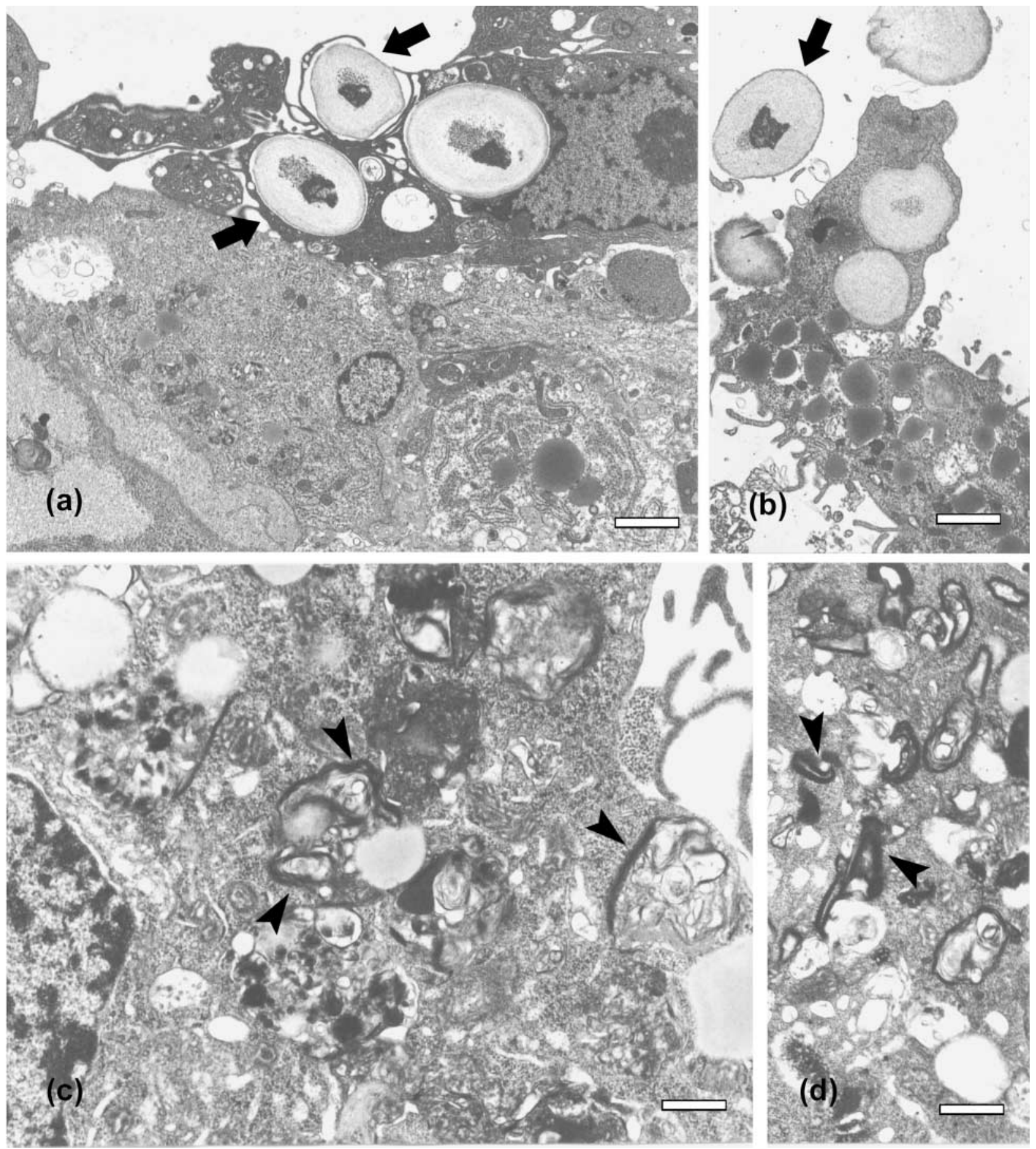

Figure 6 Electron micrographs showing part of a trophoblast cell cytoplasm $6 \mathrm{~h}$ after the inoculation of (c, d) E. coli and (a, b) zymosan particles into the culture system. Note that, whereas zymosan can be easily distinguished in different stages of internalization (arrows) in the cytoplasm of trophoblast cells, only cellular debris (arrowheads) is seen in the cytoplasm of cells that received $E$. coli. Scale bars represent: (a, b) $1.5 \mu \mathrm{m}$, (c) $0.7 \mu \mathrm{m}$, (d) $0.5 \mu \mathrm{m}$.

significant increase of 1.3 -fold at both 6 and $24 \mathrm{~h}$ of the treatment $(P<0.05)$. The concomitant presence of IFN- $\gamma$ and $\mathrm{C} 3$ led to synergistic increases in phagocytosis rates during all experimental periods (Fig. 3g-h, Fig. 4), but the most pronounced effect occurred after $2 \mathrm{~h}$ of treatment (4.2-, 2.4- and 2.3-fold increases after 2, 6 and $24 \mathrm{~h}$ respectively, $P<0.05)$.
The patterns of adhesion and phagocytosis of E. coli and zymosan were similar, although a faster phagocytosis rate was observed for bacteria (Fig. 5). Internalized particles could be seen as soon as $1 \mathrm{~h}$ after introducing the bacteria to the culture. After $3 \mathrm{~h}$, these particles became quite prominent in the trophoblast giant and non-giant cells (Fig. 5a,b). At $6 \mathrm{~h}$ after bacterial inoculation, the 
trophoblast cytoplasm showed either scarce particles or diffusely fragmented fluorescent debris (Fig. 5c,d). In addition to the cell morphology, the presence of cytokeratin filaments was used to verify the trophoblastic nature of the phagocytic cells (Fig. 5e-h). At the ultrastructural level, these temporal differences could also be seen (Fig. 6). At $6 \mathrm{~h}$ after bacteria inoculation, the cytoplasm of the trophoblast cells exhibited a large number of phagosomic vacuoles containing heterogeneous, unrecognizable material (Fig. 6c,d), whereas recognizable particles still in the process of internalization were frequently seen in the samples receiving zymosan particles (Fig. 6a,b).

\section{Discussion}

The present study was undertaken to determine whether trophoblast cells are able to maintain phagocytic activity after placental maturation and to increase understanding of the physiological significance and the role of this event in the reproductive process.

Particles of $S$. cerevisiae (zymosan) were used for the in vivo experimental design because they are easily recognizable in light and electron microscopic analysis and are not capable of invading cells, thus assuring that the internalized particles result from phagocytosis. During the first $24 \mathrm{~h}$ following inoculation, yeast cells were found in the blood, spleens and placentas of the pregnant host animals. In those same animals, leukocytes, macrophages and trophoblast cells showed conspicuous signs of phagocytosis, with or without thioglycolate activation of macrophages. At the placental level, the onset of yeast cell phagocytosis by leukocytes and trophoblast cells began as early as $3 \mathrm{~h}$ after inoculation. The yeast cell phagocytosis was faster than that described for pathogenic bacteria such as Coxiella burnetti, Chlamydia psittaci, Listeria monocytogenes and Brucella abortus (Redline \& Lu 1988, Baumgartner \& Bachman 1992, Tobias et al. 1993, Buendia et al. 1998). It is possible that these microorganisms have defense mechanisms for avoiding immediate recognition by the immunological defense system of the host organism. In the case of S. cerevisiae in particular, this is an unexpected finding.

Treatment with thioglycolate did not significantly alter the pattern of yeast phagocytosis by either leukocytes and/or placental cells, but did appear to interfere with the kinetics of the process. Phagocytosis was triggered earlier in the thioglycolate-treated animals, suggesting that macrophages may, either directly or indirectly, orchestrate the phagocytic process in other cell types, including placental cells. This may be particularly significant in the case of trophoblast cells because it is indicative of a maternal-fetal dialogue through regulatory molecules of the maternal defense system. Direct stimulation of the trophoblast by thioglycolate might also be involved in this activation. However, in our in vitro studies (data not shown), we found no evidence of such a mechanism.

Using primary placental cell cultures, we also identified and estimated the proportion of trophoblast cells involved in phagocytosis under different situations. Cytokeratin A-B (CK) immunolocalization (Brület et al. 1980) and morphological analysis were employed in order to verify the lineage of the phagocytic cells. Although phagocytosis was immediately observed when yeast cells or E. coli were added to the system, E. coli particles were apparently internalized more rapidly than were zymosan particles. Phagocytosis of $E$. coli peaked $3 \mathrm{~h}$ after the bacteria were introduced into the culture system, whereas maximum yeast phagocytosis was achieved at approximately $6 \mathrm{~h}$ after culture inoculation. The reasons for these differences are unclear, but may involve recognition, attachment and mechanisms for internalization and degradation - all dependent upon the nature of the target organisms. In this model system, trophoblast giant cells (giant, CK+ individual cells) and trophoblast cells that are morphologically compatible with those present in the labyrinth zone (small, clustered CK+ cells) exhibit phagocytosis. In normal gestation, labyrinth cells are usually involved in metabolic exchange rather than in phagocytic activity. However, Athanassakis et al. (1987) reported some phagocytic activity in the labyrinth, suggesting that these cells may be endowed with this ability as an additional nutritional mechanism.

The ability of trophoblast cells to phagocytose was also tested by using phagocytic mediators such as IFN- $\boldsymbol{y}$ and complement component C3. Results of morphological and quantitative analyses suggest that both treatments enhanced the phagocytic rate, indicating an increase in the number of cells exhibiting microorganisms within phagosomes, as well as in the number of phagosomes per cell. In comparison with IFN- $\gamma, \mathrm{C} 3$ protein appeared to stimulate a greater number of cells to phagocytose. However, the highest phagocytic levels were obtained using both treatments concomitantly, suggesting that their effects are synergistic.

The IFN- $\gamma$-mediated phagocytic response observed here might be a direct consequence of IFN- $\gamma$ receptor $\alpha$ and $\beta$ chains up-regulation in the function of the IFN- $\gamma$ treatment. Similar up-regulation has been described in macrophages (Mantovani, 1981, 1987, Hiraí et al. 1985, Heyworth \& Badwey 1990, Lewis \& McGee 1992) and in early stages of gestation (Albieri et al. 1999, 2001). In our laboratory, studies investigating the possibility that upregulation may also occur in placental trophoblast cells are currently underway.

Involvement of the C3 protein in the phagocytic process of trophoblast cells is notable, but not unique. In a receptor-specific mediated process, C3b-opsonized particles have been shown to be more susceptible to recognition, adhesion and phagocytosis (Bianco et al. 1975, Mantovani 1987). In the present study, we were also able clearly to associate the presence of C3-opsonized particles with increased numbers of internalized particles in the trophoblast cell population, implying that these molecules facilitate trophoblast cell phagocytosis in a similar process. Although we did not analyze expression of C3b receptor in placental cells, this receptor has been 
detected at the trophoblast giant-cell surface in the earlier stages of gestation (Albieri et al. 1999). This and other evidence in the literature (Athanassakis et al. 1987, Drake \& Rodger 1987, Guilbert et al. 1993, Albieri et al. 1999, 2001, Guleria \& Pollard 2000, Sasmono et al. 2003) strengthens the argument that trophoblast cells play roles in placental defense mechanisms. In mice, CSF-1 of maternal origin interacts with trophoblast cells, inducing the synthesis of neutrophil chemoattractants and macrophage inflammatory protein-2, both of which are potent mediators of the maternal immune response against bacterial infection (Guleria \& Pollard 2000). Moreover, T-lymphocytes act on trophoblast cells, stimulating them to proliferate and to exhibit phagocytic behavior (Athanassakis et al. 1987).

Taken together, these data clearly indicate that placental trophoblast cells are not only able to express phagocytosis in vivo and in vitro but, when properly stimulated via various activation pathways, are also capable of increasing phagocytic activity. Our results also corroborate other findings that suggest a trophoblast defense mechanism (Athanassakis et al. 1987, Drake \& Rodger 1987, Guilbert et al. 1993, Albieri et al. 1999, 2001, Guleria \& Pollard 2000). We conclude that these cells are capable of selectively removing microorganisms from the maternal-fetal interface and in a culture environment.

\section{Acknowledgements}

This work was supported by grants from FAPESP and CNPq. We would like to thank Rosangela de Oliveira, Gaspar Lima, Roberto Cabado and Edson Rocha de Oliveira for providing excellent technical assistance. We also thank Renata Luder de Oliveira for assistance in the construction of the GFP plasmid, Dr Benedito Correa for providing the Saccharomyces cerevisiae and Jefferson Davis Boyles for editorial assistance. In addition, we are grateful to Dr Aureo Yamada, Dr Dânia Hamassaki Britto and Dr Emer Ferro for generously granting access to the laboratory facilities.

\section{References}

Albieri A \& Bevilacqua E 1996 Induction of erythrophagocytic activity in cultured mouse trophoblast cells by phorbol myristate acetate and all-trans-retinal. Placenta 17 507-512.

Albieri A, Kipnis T \& Bevilacqua E 1999 Possible role of activated complement component $\mathrm{C}_{3}$ in phagocytic activity exhibited by the mouse trophoblast. American Journal of Reproductive Immunology $41343-352$.

Albieri A, Amarante AM, Gagioti S \& Bevilacqua E 2001 In vitro behavior of post implanting and placental trophoblast cells during zymosan challenging and interferon- $\gamma$ stimulation. Placenta $\mathbf{2 2}$ A11.

Athanassakis I, Bleackley RC, Patetkau V, Guilbert L, Barr PJ \& Wegmann TG 1987 The immunostimulatory effect of T cells and T cell lymphokines on murine fetally derived placental cells. Journal of Immunology 138 37-44.

Athanassakis I, Chaouat G \& Wegmann TG 1990 The effects of antiCD4 and CD-8 antibody treatment on placental growth and function in allogeneic and syngeneic murine pregnancy. Cellular Immunology 129 13-21.
Athanassakis I, Papamatheakis J, Bouris G \& Vassiliadis S 2000 Interferon-gamma induces differentiation of ectoplacental cone cells to phenotypically distinct trophoblasts. Developmental Comparative Immunology 24 633-672.

Athanassakis-Vassiliadis I, Papamatheakis J \& Vassiliadis S 1993 Specific CSF-1 binding on murine placental trophoblasts and macrophages serves as a link to placental growth. Journal of Receptor Research 13 739-751.

Baumgartner W \& Bachman N 1992 Histological and immunocytochemical characterization of Coxiella burnet - associated lesions in the murine uterus and placenta. Infection and Immunity $\mathbf{6 0}$ 5232-5241.

Bevilacqua E \& Abrahamsohn PA 1988 Ultrastructure of trophoblast giant cell transformation during the invasive stage of implantation of the mouse embryo. Journal of Morphology 198 341-351.

Bevilacqua E \& Abrahamsohn PA 1989 Trophoblast invasion during implantation of the mouse embryo. Archivos de Biología y Medicina Experimentales 22 107-108.

Bianco C, Griffi FM Jr \& Silverstein C 1975 Studies of the macrophage complement receptor: alteration of receptor function upon macrophage activation. Journal of Experimental Medicine 141 1278-1290.

Billington WD 1971 Biology of the trophoblast. In Advances in Reproductive Physiology, pp 27-66. Ed. MNH Bishop. London: Logos Press.

Brület P, Babinet C, Kemler R \& Jacob F 1980 Monoclonal antibodies against trophectoderm-specific markers during mouse blastocyst formation. PNAS 77 4113-4117.

Buendia AJ, Sanchez J, Martinez M, Camara P, Navarro JA, Rodolakis A \& Salinas J 1998 Kinetics of infection and effects on placental cell populations in a murine model of Chlamydia psittaci-induced abortion. Infection and Immunity 66 2128-2134.

Call DR, Nemzek JK, Ebong SJ, Bolgos GL, Newcomb DE \& Remick DG 2001 Ratio of local to systemic chemokine concentrations regulates neutrophil recruitment. American Journal of Pathology 158 715-721.

Clark DA, Yu G, Arck PC \& Gorezynski RM 2003 MD-1 is a critical part of the mechanism causing $\mathrm{TH}-1$ cytokine-triggered murine fetal loss syndrome. American Journal of Reproductive Immunology 49 297-307.

Cohen MS, Ryan JL \& Root RK 1981 The oxidative metabolism of thioglycolate-elicited macrophages: the relationship between oxygen, superoxide and hydrogen peroxide and the effect of monolayer formation. Journal of Immunology 127 1007-1011.

Cohn ZA 1978 The activation of mononuclear phagocytes: fact, fancy and future. Journal of Immunology 121 813-816.

Drake BL \& Rodger JC 1987 Phagocytic properties of cultured murine trophoblast. Placenta 8 129-134.

Enders AC \& Schlafke S 1969 Cytological aspects of trophoblast uterine interactions in early implantation. American Journal of Anatomy 125 1-29.

Gagioti S, Colepicolo P \& Bevilacqua E 1995 Post implantation mouse embryos have the capability to generate and release reactive oxygen species. Reproduction, Fertility and Development 7 1111-1116.

Gagioti S, Colepicolo P \& Bevilacqua E 1996 Reactive oxygen species and the phagocytosis process of hemochorial trophoblast. Ciência e Cultura 48 37-42.

Gagioti S, Scavone C \& Bevilacqua E 2000 Participation of the mouse implanting trophoblast in nitric oxide production during pregnancy. Biology of Reproduction 62 260-268.

Guilbert L, Robertson SA \& Wegmann TG 1993 The trophoblast as an integral component of macrophage-cytokine network. Immunology Cell Biology 71 49-57.

Guleria I \& Pollard JW 2000 The trophoblast is a component of the innate immunosystem during pregnancy. Nature Medicine 6 589-593.

Heyworth PG \& Badwey JA 1990 Protein phosphorylation associated with the simulation of neutrophils. Modulation of superoxide 
production by protein kinase $\mathrm{C}$ and calcium. Journal of Bioenergetics and Biomembranes 22 1-26.

Hiraí K, Ohno Y \& Ogawa K 1985 Cytochemistry of hydrogen peroxide production by cultured activated macrophages in phagocytosis. Acta Histochemica et Cytochemica 18 69-75.

Kanai-Azuma M, Kanai Y, Kurohmaru M, Tachi C, Yazaki K \& Hayashi Y 1994 Giant cell transformation of trophoblast cells in mice. Endocrine Journal 41(Suppl) 33-41.

Kohchi C, Mizuno D \& Soma G 1991 Expression of TNF-alpha and TNF-beta transcripts in murine embryonal carcinoma cells and trophoblast cell. Nucleic Acids Symposium Series 25 119-120.

Lewis C \& McGee JOD 1992 The Macrophage. Oxford: IRL Press.

Lima AO \& Dias-da-Silva W 1970 Immunologia, Imunopatologia, Alergia - Métodos. Rio de Janeiro: Guanabara Koogan.

Mantovani B 1981 Phagocytosis of immune complex mediated by $\operatorname{IgM}$ and $\mathrm{C} 3 \mathrm{~b}$ by macrophages from mice treated with glycogen. Journal of Immunology 126 127-130.

Mantovani B 1987 Phagocytosis of in vitro-aged erythrocytes: a sharp distinction between activated and normal macrophage. Experimental Cell Research 173 282-288.

Mehrotra PK 1988 Ultrastructure of mouse ectoplacental cone cells. Biological Structures and Morphogenesis 1 63-68.

Muntener M \& Hsu YC 1977 Development of trophoblast and placenta in the mouse. Acta Anatomica 98 241-252.

Ouahrani-Bettache S, Porte F, Teyssier J, Liautard JP \& Kohler S 1999 pBBR1-GFP: a broad-host-range vector for prokaryotic promoter studies. Biotechniques 26 620-622.

Paulesu L, King A, Loke YW, Cintorino M, Bellizzi E \& Boraschi D 1991 Immunohistochemical localization of IL-1 beta in normal human placenta. Lymphokine Cytokine Research 10 443-448.

Pavia CS 1983 Expression of cell-mediated antimicrobial immunity by mouse trophoblast monolayers. Journal of Infection Diseases 146 1006-1010.

Redline RW \& Lu CY 1988 Specific defects in the anti-lysterial immune response in discrete regions of the murine uterus and placenta account for susceptibility to infection. Journal of Immunology $1403947-3955$.

Salins S, Newlon C, Winden P, Klein TW \& Friedman H 2001 Differential induction of gamma interferon in Legionella pneumophila infected macrophages from $\mathrm{Balb} / \mathrm{c}$ and $\mathrm{A} / \mathrm{J}$ mice. Infection and Immunity 69 3605-3610.

Sasmono RT, Oceandy D, Pollard JW, Tong W, Pavli P, Wainwright BJ, Ostrowski MC, Himes SR \& Hume DA 2003 A macrophage colony-stimulating factor receptor green fluorescent protein transgene is expressed throughout the mononuclear phagocyte system of the mouse. Blood 101 1155-1163.

Schaffer I, Scheid A, Spielmann P, Breymann C, Zimmermann R, Meudi M, Gassmann M, Marti HH \& Wenger RH 2003 Oxygenregulated expression of TGF-beta 3, a growth factor involved in trophoblast differentiation. Placenta 24 941-950.

Sharma RK 1998 Mouse trophoblast cell lines: I - relationship between invasive potential and TGF-beta 1. In Vivo 12 431-440.

Simmons RL \& Russell PS 1962 The antigenicity of mouse trophoblast. Annals of New York Academy of Sciences 99 717-732.

Soares MJ \& Glasser SR 1987 Placental lactogen production and functional differentiation of rat trophoblast cells in vitro. Journal of Reproduction and Fertility 79 335-341.

Soares MJ, Faria TN, Hamilin GP, Lu XJ \& Deb S 1993 Trophoblast cell differentiation: expression of the placental prolactin family. In Trophoblast Cells: Pathways for Maternal-Embryonic Communications, pp 45-67. Eds MJ Soares, S Handwerger \& F Talamares. New York: Springer-Verlag.

Soares MJ, Chapman BM, Rasmussen CA, Tamei T \& Orwing KE 1996 Differentiation of trophoblast endocrine cells. Placenta 17 277-289.

Tobias L, Cordes DO \& Schuring GG 1993 Placental pathology of the pregnant mouse inoculated with Brucella abortus strain 2308. Veterinary Pathology 30 119-129.

Welsh AO \& Enders AC 1987 Trophoblast-decidual cell interaction and establishment of maternal blood circulation in the parietal yolk sac placenta of the rat. Anatomical Record 217 203-219.

Whiteside FJ, Boucaut KJ, Teh A, Garcia-Aragon J, Harvey MB \& Herington AC 2003 Elevated concentration of TNF-alpha induces trophoblast differentiation in mouse blastocyst outgrowths. Cell and Tissue Research 314 275-280.

Yamaguchi M, Sawada K \& Miyake A 1996 Lipopolysaccharides selectively inhibit mouse placental lactogen-Il secretion through stimulation of interleukin-1 alpha (IL-1 alpha) and IL-6 production. Journal of Endocrinological Investigation 7 415-421.

Received 12 September 2003

First decision 30 October 2003

Revised manuscript received 1 April 2004

Accepted 26 April 2004 